\title{
Electrical Conductivity Testing as Applied to the Assessment of Freshly Collected Kielmeyera coriacea Mart. Seeds
}

\author{
Kennya Mara Oliveira Ramos, ${ }^{1}$ Juliana M. M. Matos, ${ }^{1}$ \\ Rosana C. C. Martins, ${ }^{1}$ and Ildeu S. Martins ${ }^{2}$ \\ ${ }^{1}$ Seed Technology Laboratory of Forestry, Department of Forestry, University of Brasilia, CP 04357, \\ 70919970 Campus Asa Norte, DF, Brazil \\ ${ }^{2}$ Department of Forestry, University of Brasilia, CP 04357, 70919970 Campus Asa Norte, DF, Brazil
}

Correspondence should be addressed to Juliana M. M. Matos, julianamartins21@yahoo.com.br

Received 17 December 2011; Accepted 14 February 2012

Academic Editors: A. Berville, C. Gisbert, J. Hatfield, and Y. Ito

Copyright (C) 2012 Kennya Mara Oliveira Ramos et al. This is an open access article distributed under the Creative Commons Attribution License, which permits unrestricted use, distribution, and reproduction in any medium, provided the original work is properly cited.

\begin{abstract}
Assessment of seed vigor has long been an important tool of seed quality control programs. The conductivity test is a promising method for assessment of seed vigor, but proper protocols for its execution have yet to be established. The objective of this study was to assess the efficiency of electrical conductivity (EC) testing as a means of assessing the viability of freshly collected Kielmeyera Coriacea Mart. seeds. The test was performed on individual seeds rather than in a bulk configuration. Seeds were soaked for different periods (30 min, $90 \mathrm{~min}, 120 \mathrm{~min}$., $180 \mathrm{~min}$, and $240 \mathrm{~min}$ ) at a constant temperature of $25^{\circ} \mathrm{C}$. Conductivity was then measured with a benchtop EC meter.
\end{abstract}

\section{Introduction}

Seeds are the primary factor of the seedling production process, despite their minor contribution to the end cost of each seedling. In order to estimate the success rate of seedling production, it is essential that seed characteristics such as vigor and germinability be known [1].

The importance of knowing the characteristics of Brazilian forest species to safer and more objective management of seedling production cannot be overstated. However, such studies are scarce, particularly in light of the vast number of species with this potential [2]. Given the intensity of anthropogenic pressure and the importance of rehabilitating disrupted or degraded environments, in-depth research of forest species is warranted.

Routine methods used for determination of seed quality and viability include germination testing and the tetrazolium test. Methods such as measurement of soak solution $\mathrm{pH}$, electrical conductivity, and potassium content of leachate, all based on the permeability of the cell membrane system, are increasingly being employed in the assessment of seed vigor, as they are reliable and fast and can thus speed the decision making process.
Electrical conductivity testing, as applied to forest seeds, has yet to be standardized. Studies conducted thus far have focused on assessment of seed soaking times, which may range from 4 to 48 hours. Even at 48 hours, the conductivity test is considered a rapid technique as compared to the germination test, which, despite its status as a widespread and firmly established method, can take anywhere from 30 to 360 days to yield results (depending on species), and is limited by factors such as dormant seeds.

The total concentration of electrolytes leached by seeds during soaking has long been assessed indirectly, mostly through the conductivity test, which takes advantage of the fact that inorganic ions make up a substantial portion of these electrolytes [3-5].

Rapid assessment of seed quality allows for preemptive decision-making during harvest, processing, sale and storage operations, thus optimizing use of financial resources throughout these processes.

K. coriacea Mart. is a species of the Clusiaceae (Gut-tiferae) family popularly known in Brazil as pau-santo (Portuguese for "holy wood"), due to its properties as a medicinal and melliferous plant and as a source of cork. In traditional 
Brazilian medicine, the leaves are used as an emollient and antitumor agent, and the resin as a tonic and in the treatment of toothache and various infections. The fruits are used in regional crafts and flower arrangements. Even if the dye is of the leaves and bark. The trunk provides cork [6].

$K$. coriaceae specimens grow to approximately 4 meters in height. The flowering period extends from January to April and the fruiting period from May to September, and seed collection can take place from September onwards. Leaves are alternate, simple, oval to elliptical, coriaceous, and clustered at the end of the branches, and feature highly visible, pink midribs. A white to off-white latex is secreted in small amounts upon removal of leaves. Flowers are white to pale pink in color, large, fragrant, with many yellow stamens and are borne in short clusters near the apex of the branches. Seedling production requires that seeds be sown shortly after collection.

In the fruit are found 60 to 80 seeds with anemochoric. The seed varies from round to oblong, winged at the ends, light brown color, has integument thin and fragile, with smooth texture, the sizes range from 4.3 to $5.6 \mathrm{~cm}$ long, 1.3 to $1.9 \mathrm{~cm}$ wide, and 0.2 to 0.5 centimeter thick. The individual weight of the seeds ranges from. 112 to. 128 grams. Nursery radicle emission occurred at 7 days and the germination rate was $90 \%$. Germination occurs within 7 to 10 days. The species is slow growing, both in the field and in a nursery setting [7].

The present study sought to assess the applicability of the conductivity test to freshly collected K. coriacea Mart. seeds by determining the optimal soak time for performance of the test and comparing results obtained with this method against those obtained by tetrazolium and germination testing of seeds from the same batch.

\section{Materials and Methods}

2.1. Seed Collection. Seeds were collected in the cerrado sensu stricto, in SCA (Clean Water Farm), area of study at the University of Brasília (UNB) in August 2010, matrixes marked with the aid of GPS, after the period of physiological maturation of the seeds. The collection of fruits was directly from the tree, with the help of trimmer, then the seeds were processed and stored in paper bags at room temperature in the laboratory.

2.2. Conductivity Test. The development of tests to evaluate the physiological quality of seeds, as well as the standardization of these is essential for the establishment of an efficient quality control [8]. One of the main requirements for the seed vigor refers to obtain reliable results in a relatively short period of time, allowing the speed of decision making especially as regards the operations of collection, processing, and marketing [9]. The literature indicates that rapid tests are most studied early events related to the deterioration of the sequence proposed by Delouche and Baskin [10] as the degradation of cell membranes and reduced activity, and biosynthetic respiratory [9]. The measurement of electrical conductivity through the electrolyte amount released by soaking seeds in water has been applied by the individual method where each seed is a sample or more often, a sample of seed representative of a population (mass method). For this case, the results represent the average conductivity of a group of seeds, may a small amount of dead seeds affect the conductivity of a batch with many high-quality seed generating a read underestimated. To minimize this problem, we recommend choosing the seeds, excluding the damaged seeds.

The electrical conductivity is based on the principle that the deterioration process is the leaching of the cells of seeds soaked in water due to loss of integrity of cellular systems. Thus, low conductivity means a high-quality seed and high conductivity, that is, greater output seed leachate, suggests that less force [11].

The electrical conductivity is not yet widely used in Brazil, its use is restricted to activities related to research (Krzyzanowski et al., 1991). There are common jobs using this test to determine the physiological quality of tree seeds. However, it is a promising vigor test for possible standardization of the methodology, at least within a species. However, it is a promising vigor test for possible standardization of the methodology, at least within a species. However, there are factors which influence the conductivity values as the size, the initial water content, temperature and time of soaking, the number of seeds per sample, and genotype [12].

Five treatments were carried out to test the efficiency of the conductivity test as a means of evaluating the viability of freshly collected K. coriacea Mart. seeds.

Five runs of 20 seeds were tested for each treatment. Seeds were individually placed into containers holding $50 \mathrm{~mL}$ of distilled water and left to soak for 30, 90, 120, 180, and 240 minutes in a germination chamber set to a constant temperature of $25^{\circ} \mathrm{C}$. The minimum time taken for the soaking of 30 minutes was adopted by the same authors and Amaral and peske [13], Fernandes et al. [14], and Matos [1] who concluded that the period of 30 minutes of soaking is more effective to estimate the germination of the seeds. After each period, the conductivity of the soak solution was immediately tested with a benchtop EC meter precise to $+/-1 \%$ (Quimis). Readings were expressed as $\mu \mathrm{S} \cdot \mathrm{cm}^{-1} / \mathrm{g}^{-1}$ seed [15].

Data thus obtained were subjected to analysis of variance with partitioning into orthogonal polynomials for analysis of the effect of soaking times on electrical conductivity.

2.3. Tetrazolium Test. The tetrazolium test, also known as biochemical test for vitality, is a technique used to estimate the viability and seed germination. A fundamental condition for ensuring the efficiency of the test is the direct contact of the tetrazolium solution with the tissues of the seed to be tested. Due to the impermeability of the coats of most forest tree seeds, it is necessary to adopt a previous preparation of the seeds that were tested. This preparation is based on facilitating entry of the solution in the seed. Among the preparations that precede the test we have cutting the seed coat, seed coat removal, scarification by sandpaper scarification by soaking in hot water and water [16]. In the previous preparation of the seeds, factors such as concentration of the solution or even the time of the staining 
TABLE 1: Conductivity ranges of freshly collected Kielmeyera coriacea Mart. seeds after soaking for different periods.

\begin{tabular}{lccccc}
\hline \multirow{2}{*}{ EC range } & \multicolumn{6}{c}{ Percentage of viable seeds in each test } \\
& $30^{\prime}$ & $90^{\prime}$ & $120^{\prime}$ & $180^{\prime}$ & $240^{\prime}$ \\
& soak & soak & soak & soak & soak \\
\hline $3-3.99 \mu \mathrm{S} \cdot \mathrm{cm} \cdot \mathrm{g}$ & $93 \%$ & $88 \%$ & - & $2 \%$ & $54 \%$ \\
$4-4.99 \mu \mathrm{S} \cdot \mathrm{cm} \cdot \mathrm{g}$ & $3 \%$ & $12 \%$ & $4 \%$ & $10 \%$ & $39 \%$ \\
$5-5.99 \mu \mathrm{S} \cdot \mathrm{cm} \cdot \mathrm{g}$ & - & - & $30 \%$ & $42 \%$ & $6 \%$ \\
$6-6.99 \mu \mathrm{S} \cdot \mathrm{cm} \cdot \mathrm{g}$ & - & - & $47 \%$ & $39 \%$ & - \\
$7-7.99 \mu \mathrm{S} \cdot \mathrm{cm} \cdot \mathrm{g}$ & - & - & $13 \%$ & $5 \%$ & - \\
$8-8.99 \mu \mathrm{S} \cdot \mathrm{cm} \cdot \mathrm{g}$ & $1 \%$ & - & $4 \%$ & $1 \%$ & - \\
$9-17.99 \mu \mathrm{S} \cdot \mathrm{cm} \cdot \mathrm{g}$ & - & - & $2 \%$ & $1 \%$ & - \\
\hline
\end{tabular}

solution can affect the efficiency of the test in the evaluation of seed quality. The time required for the development of appropriate color according to the Rules for Seed Analysis [16] varies depending on each species, can be between 30 and 240 minutes.

The tetrazolium test has been widely used in seeds of various species due to the speed and efficiency in the characterization of the viability and vigor, and the possibility of damage to the same distinction, assisting in the process of quality control from the steps of harvest storage (GRIS et al, 2007).

The tetrazolium test was also applied to freshly collected K. coriacea Mart. seeds, for a total of three runs and 20 seeds. Seeds were soaked in a $0.5 \%$ solution of 2,3,5-triphenyl-2Htetrazolium for 24 hours in a germination chamber set to a constant temperature of $25^{\circ} \mathrm{C}$. After each run, seeds were washed, bisected, and the half-containing the embryonic axis placed under a stereo viewer for examination of staining patterns [17].

2.4. Germination Test. The standard germination test is the official procedure to evaluate the ability of seeds to produce normal seedlings under favorable conditions in the field, but does not always reveal differences in quality and performance among seed lots, which can manifest in storage or in the field [18].

During the germination test optimum conditions are provided and controlled for seeds to encourage the resumption of metabolic activity which will result in the seedlings. The main objective of the germination test is the information about the quality of seeds, which is used in the identification of lots for storage and sowing [19].

Freshly collected $K$. coriacea Mart. seeds were placed in a germination chamber at a constant temperature of $25^{\circ} \mathrm{C}$ (Treatment 1) or an alternating temperature of $20-30^{\circ} \mathrm{C}$ (Treatment 2), on a standard cycle of 8 hours of light and 16 hours of dark. Each test consisted of five runs and was performed on 20 seeds.

Germination was defined as emergence of at least $2.0 \mathrm{~mm}$ of the primary root [20]. Assessment was conducted daily, and emergence was observed between day 6 and day 7 . At the end of the 14-day test period, the germination percentage was calculated on the basis of radicle emergence [21].
TABle 2: Percentage of viable Kielmeyera coriacea Mart. seeds according to EC range.

\begin{tabular}{lcc}
\hline Soak time (min.) & EC $\left(\mu \mathrm{S} \cdot \mathrm{cm}^{-1} \cdot \mathrm{g}^{-1}\right)$ & $\begin{array}{c}\text { Percentage of viable } \\
\text { seeds }(\%)\end{array}$ \\
\hline $30^{\prime}$ & $2-6.99 \mu \mathrm{S} \cdot \mathrm{cm}^{-1} \cdot \mathrm{g}^{-1}$ & $99 \%$ \\
& $7-17.99 \mu \mathrm{S} \cdot \mathrm{cm}^{-1} \cdot \mathrm{g}^{-1}$ & $1 \%$ \\
$90^{\prime}$ & $2-6.99 \mu \mathrm{S} \cdot \mathrm{cm}^{-1} \cdot \mathrm{g}^{-1}$ & $100 \%$ \\
& $7-17.99 \mu \mathrm{S} \cdot \mathrm{cm}^{-1} \cdot \mathrm{g}^{-1}$ & - \\
$120^{\prime}$ & $2-6.99 \mu \mathrm{S} \cdot \mathrm{cm}^{-1} \cdot \mathrm{g}^{-1}$ & $81 \%$ \\
& $7-17.99 \mu \mathrm{S} \cdot \mathrm{cm}^{-1} \cdot \mathrm{g}^{-1}$ & $19 \%$ \\
$180^{\prime}$ & $2-6.99 \mu \mathrm{S} \cdot \mathrm{cm}^{-1} \cdot \mathrm{g}^{-1}$ & $93 \%$ \\
& $7-17.99 \mu \mathrm{S} \cdot \mathrm{cm}^{-1} \cdot \mathrm{g}^{-1}$ & $7 \%$ \\
$240^{\prime}$ & $2-6.99 \mu \mathrm{S} \cdot \mathrm{cm}^{-1} \cdot \mathrm{g}^{-1}$ & $100 \%$ \\
& $7-17.99 \mu \mathrm{S} \cdot \mathrm{cm}^{-1} \cdot \mathrm{g}^{-1}$ & - \\
\hline
\end{tabular}

(a) Germination percentage: $\% G$ :

$$
G(\%)=\frac{N}{A} \times 100,
$$

with $N=$ number of germinated seeds and $A=$ total number of seeds tested.

\section{Results}

3.1. Conductivity Test. Different soaking times were not associated with any significant differences in conductivity results in K. coriacea Mart. seeds (Table 1).

Seeds with a leachate conductivity range of 7-17.99 $\mu \mathrm{S} \cdot \mathrm{cm} \cdot \mathrm{g}$ were considered nonviable, confirming the hypothesis behind conductivity testing, which is the nonvi-able seeds that have higher soaking solution conductivity values (Table 2).

Analysis of variance revealed a low coefficient of variation $(20.26 \%)$, which suggests good experimental control (Table 3).

After analysis of variance, the correlation between the soaking time and electrical conductivity variables was assessed. The cubic model yielded $R^{2}=0.75$, which is indicative of a positive correlation between the study variables.

The following equation was obtained on the basis of the cubic model:

$$
E C=4.1408-0.04469 t+0.000737 t^{2}-0.0000023 t^{3} .
$$

Analysis of a plot of the above function in the GeoGebra 2007 software package shows that variation in electrical conductivity as a function of soaking time is minor and approaches a constant, which is consistent with the study results, in which changes in soaking time had no influence on conductivity (Figure 1).

Matos [1] reported that a 30-minute soak was enough for assessment of Anadenanthera falcata, Copaifera langsdorffi, and Enterolobium contortisiliquum seeds by the soaking solution $\mathrm{pH}$ method- that is, the amount of matter leached after this period sufficed for measurement.

Although the principle of conductivity is the same used for the test $\mathrm{pH}$ of exudate, the soaking time needed to 
TABLE 3: Analysis of variance of various soaking times for electrical conductivity testing of Kielmeyera coriacea Mart. seeds.

\begin{tabular}{lcccccc}
\hline Source of variation & DF & SS & RMS & F & Mean & CV \\
\hline Treatment & 4 & 815.0123 & 203.7531 & 171.425 & 4.71 & 20.26 \\
Residual & 495 & 450.7860 & 0.910678 & - & - & - \\
\hline
\end{tabular}

DF: degrees of freedom; SS: sum of squares; RMS: root mean square; F: test statistic; CV: coefficient of variation; SD: standard deviation.

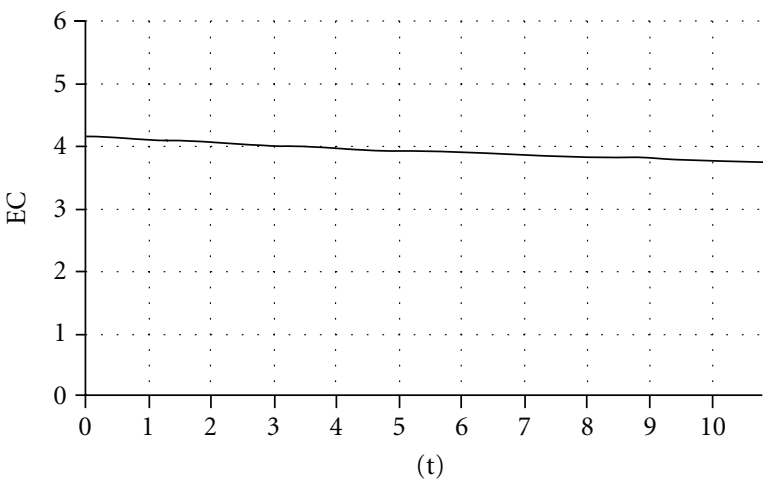

FIGURE 1: Leachate conductivity as a function of soaking time in Kielmeyera coriacea Mart. seeds.

analyze the differential seeds through the conductivity may be explained by the fact that this technique is quantitative, while $\mathrm{pH}$ in the art exudate analyzes are qualitative. In other words to the technique of $\mathrm{pH}$ values of the exudate it is important to detect the acidity of imbibition while on the electrical conductivity we draw a comparison between the analyzed values to separate viable from nonviable samples. To determine a value of electrical conductivity as a reference to determine viable seeds are to be considered the values obtained for fresh seeds and seeds stored.

The thickness of the K. coriacea Mart. seed coat may also have affected the soaking procedure; this species has very thin seed coats, which makes soaking a very fast process.

These results are consistent with those reported by Rodrigues [22], who subjected stored K. coriacea Mart. seeds to the conductivity test and found that 90 minutes is an appropriate soaking time for analysis.

Therefore, it can be inferred that for seed Kielmeyera coriacea Mart. the soaking time of 90 minutes can be applied to obtain satisfactory results.

3.2. Tetrazolium Test. Table 4 shows the results of tetrazolium testing of $K$. coriacea Mart. seeds in our sample. The mean viability rate was $96.6 \%$. The testing procedure was based on Brazilian Ministry of Agriculture recommendations [17].

The results of the tetrazolium test were quite similar to those obtained with the conductivity method, thus confirming the efficiency of the latter method as a means for assessing the viability of $K$. coriacea Mart. seeds.

3.3. Germination Test. The germination test results of freshly collected K. coriacea Mart. seeds are shown in Table 5.
TABle 4: Tetrazolium testing of Kielmeyera coriacea Mart. seeds.

\begin{tabular}{lc}
\hline Runs & TZ \\
\hline 1 & $100 \%$ \\
2 & $90 \%$ \\
3 & $100 \%$ \\
Mean & $\mathbf{9 6 . 6} \%$ \\
\hline
\end{tabular}

Table 5: Germination test results of Kielmeyera coriacea Mart. seeds.

\begin{tabular}{lcc}
\hline Runs & $\begin{array}{c}\text { Treatment 1 } \\
\text { constant temp. } \\
\left(25^{\circ} \mathrm{C}\right)\end{array}$ & $\begin{array}{c}\text { Treatment 2 } \\
\text { alternating } \\
20-30^{\circ} \mathrm{C}\end{array}$ \\
\hline 1 & $100 \%$ & $85 \%$ \\
2 & $100 \%$ & $85 \%$ \\
3 & $100 \%$ & $100 \%$ \\
4 & $100 \%$ & $90 \%$ \\
5 & $100 \%$ & $95 \%$ \\
Total & $\mathbf{1 0 0} \%$ & $\mathbf{9 1 \%}$ \\
\hline
\end{tabular}

Regardless of temperature, both test batches exhibited good viability, and no seed dormancy was detected.

Radicle emergence was observed between day 7 and day 9 of the test, according to the analysis criteria proposed by Labouriau [21].

These findings are consistent with those of Melo et al., [23] who reported high and relatively rapid germination rates for $K$. coriacea seeds kept at $25^{\circ} \mathrm{C}$ on paper towels, with emergence of a perfect radicle on the 7 th day of assessment.

\section{Conclusions}

The electrical conductivity can be used as an indicator of seed viability and presents two advantages: to provide rapid and reliable results and the technique is not destructive and can use the seeds after the conductivity test, so they can be used to produce seedlings.

The present study showed that different soaking times had no effect on the results of conductivity testing of freshly collected $K$. coriacea Mart. seeds, suggesting that the amount of leached matter was never below the threshold required for adequate testing.

Electrical conductivity testing proved to be a feasible option for viability testing of $K$. coriacea Mart. seeds, as the results obtained with conductivity testing were confirmed by germination testing and by the tetrazolium test. 


\section{References}

[1] J. M. M. Matos, Evaluation of pH test on exudate check feasibility of forest seeds, dissertation, University of Brasília, Brasília, Brazil, 2009.

[2] F. Poggiani, S. Bruni, and E. S. Q. Barbos, "Effect of shading on seedling growth of three species forest," in National conference on native plants, vol. 2, pp. 564-569, Institute of Forestry, 1992.

[3] M. B. Mcdonald Jr. and D. O. Wilson, "ASA-610 ability to detect changes in soybean seed quality," Journal of Seed Technology, vol. 5, no. 1, pp. 56-66, 1980.

[4] S. Matthews and A. Powell, "A eletrical conductivity test," in Handbook of Vigor Test Methods, D. A. Perry, Ed., pp. 37-42, International Seed Testing Associaty, Zurich, Switzerland, 1981.

[5] J. Son Mark, W. R. Singh, A. D. C. Novembre, and H. M. C. P. Chamma, "Comparative studies to evaluate dem'etodos physiological quality of soybean seeds, with emphasis the electrical conductivity test," Brazilian Journal of Agricultural Research, vol. 25, no. 12, pp. 1805-1815, 1990.

[6] S. R. Singh, A. P. Silva, C. B. Munhoz et al., Guide of Cerrado Plants Used in the Chapada Veadeiros, WWF-Brazil, Brasilia, Brazil, 2001.

[7] J. M. Felfili, C. W. Fagg, J. C. S. Silva et al., Plants of the APA Gama Cabeça de Veado: Species, ecosystems and recovery, University of Brasilia, Brasília, Department of Engineering Forest, Brasília, Brazil, 2002.

[8] M. F. B. Muniz et al., "Comparison of methods for evaluating the physiological and health quality of melon seeds," Journal of Seeds, Pellets, vol. 26, no. 2, pp. 144-149, 2004.

[9] D. C. F. S. Dias and J. Marcos Filho, "Electrical conductivity to assess seed vigor of soybean (Glycine max (L.) Merrill)," Scientia Agricola, vol. 53, no. 1, Article ID article id, pp. 31-42, 1996.

[10] J. C. Delouche and C. C. Baskin, "Acelerated aging techniques for predicting the relative storability of seed lots," Seed Science and Technology, vol. 1, no. 2, pp. 427-452, 1973.

[11] R. D. Vieira and F. C. Krzyzanowski, "Electrical conductivity test," in Seed Vigor: Concepts and Tests, F. C. Krzyzanowski, R. D. Vieira, and J. B. França Neto, Eds., pp. 4.1-4.26, Abrates, London, UK, 1999.

[12] R. D. Vieira, "Electrical conductivity test," in Seed Vigor Tests, R. D. Vieira and N. M. Carvalho, Eds., p. 103, FUNEP, Jaboticabal, Brazil, 1994.

[13] A. S. Amaral and S. T. Peske, "Exudate $\mathrm{pH}$ to estimate, in 30 minutes seed viability of soybeans," Journal of seeds, vol. 6, no. 3, pp. 85-92, 1984.

[14] E. J. Fernandes, R. Sader, and N. M. Carvalho, "seed viability beans (Phaseolus vulgaris L.) estimated by the $\mathrm{pH}$ of the exudate," in Congress Brazil's Seeds, Gramado, Brazil, 1987.

[15] F. C. Krzyzanowski and R. D. Vieira, "Electrical conductivity test," in Seed Vigor: Concepts and Tests, F. C. Krzyzanowski, R. D. Vieira, and J. B. France Neto, Eds., pp. 4.1-4.26, Abrates, London, UK, 1999.

[16] Ministry of Agriculture, Livestock and Supply, Rule for seed testing, SNPA/DNPV/CLAV, Brasilia, Brazil, 1992.

[17] Ministry of Agriculture, Livestock and Supply, Rule for seed testing, SNPA/DNPV/CLAV, Brasilia, Brazil, 2009.

[18] N. M. Carvalho and J. Nakagawa, Seeds: Science, Technology and Production, FUNEP, Jaboticabal, Brazil, 2000.

[19] Pina-Rodrigues et al., "Quality test," in Germination from Basic to Applied, A. Ferreira and G. F. Borghetti, Eds., pp. 283-297, 2004.
[20] A. G. Ferreira and F. Borghetti, from basic to Germination applied, Artmed, Porto Alegre, Brazil, 2004.

[21] L. G. Labouriau, seed germination, OAS, Washington, DC, USA, 1983.

[22] L. L. Rodrigues, Study of imbibition time for application the method of electrical conductivity in the verification of the feasibility forest seeds stored, monograph, University of Brasília, Brasília, Brazil, 2010.

[23] J. T. Melo, J. F. Ribeiro, and V. L. G. F. Lima, "Germination of Seeds of some tree species native to the Cerrado," Journal of Seeds, vol. 1, no. 2, pp. 8-12, 1979. 


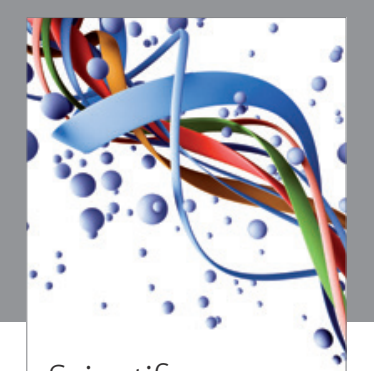

Scientifica
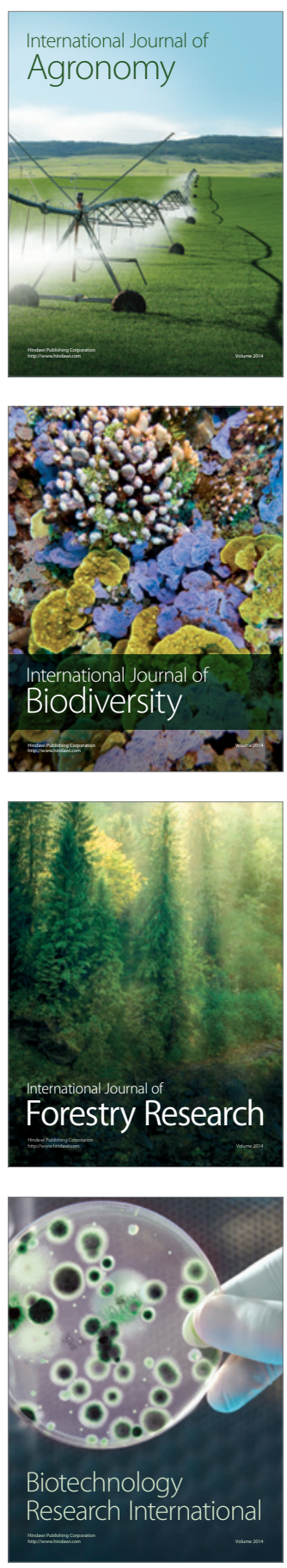
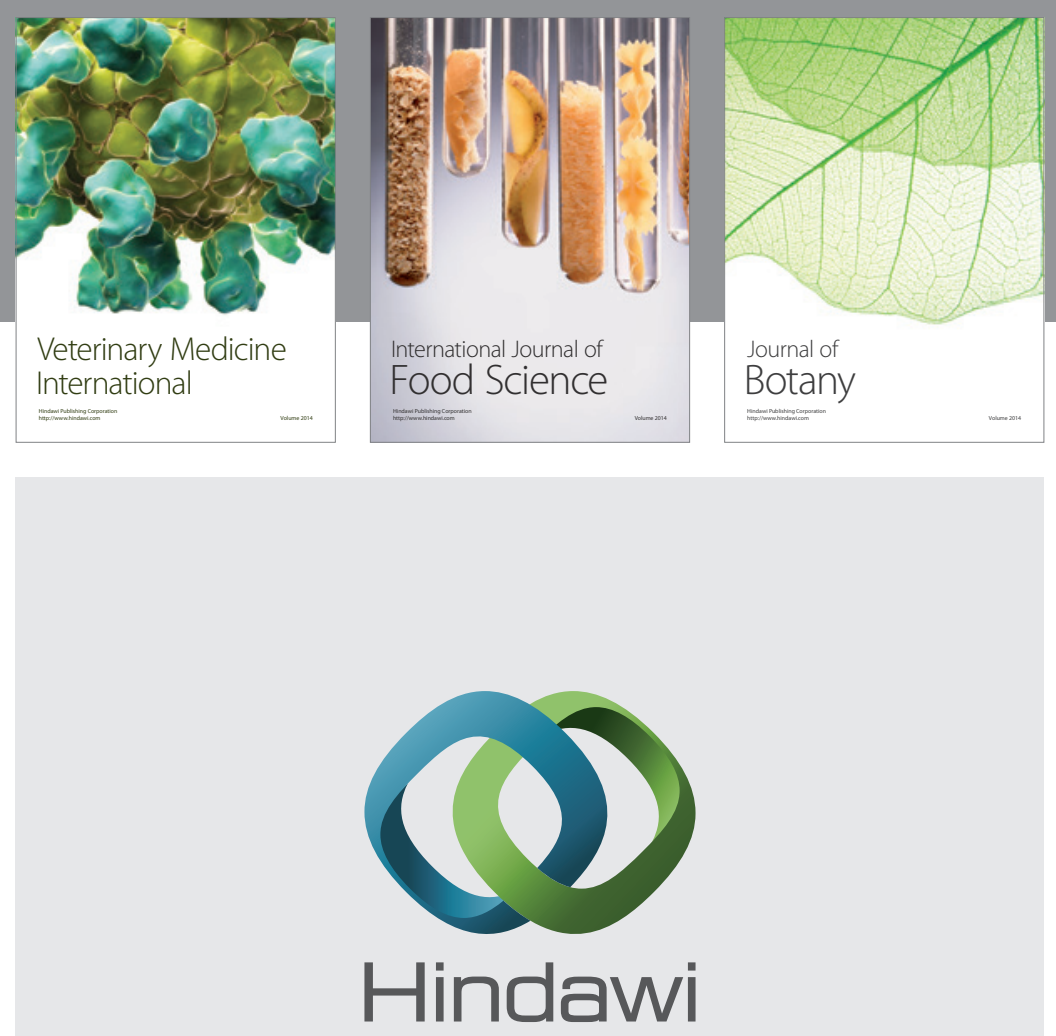

Submit your manuscripts at

http://www.hindawi.com
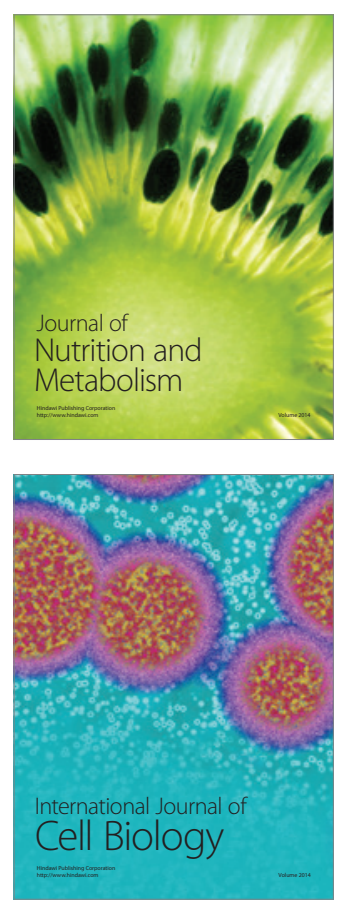
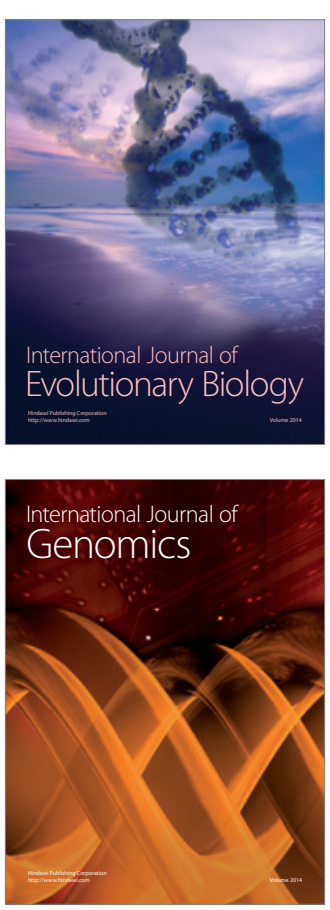
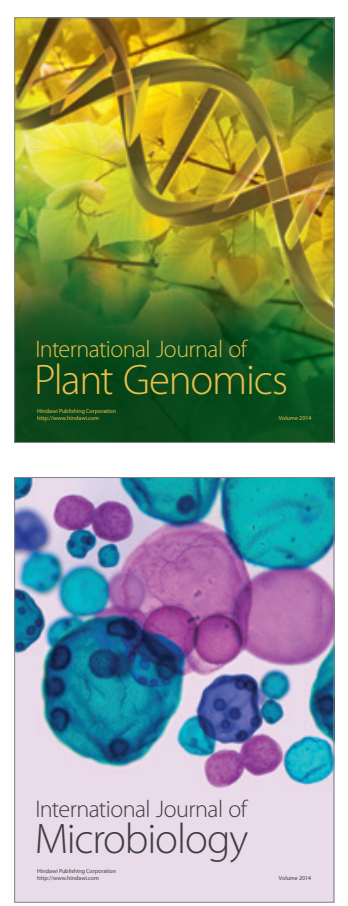

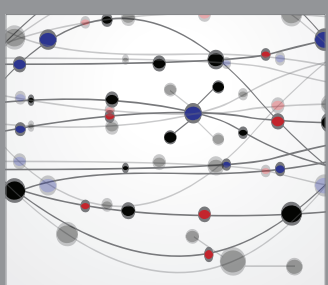

The Scientific World Journal
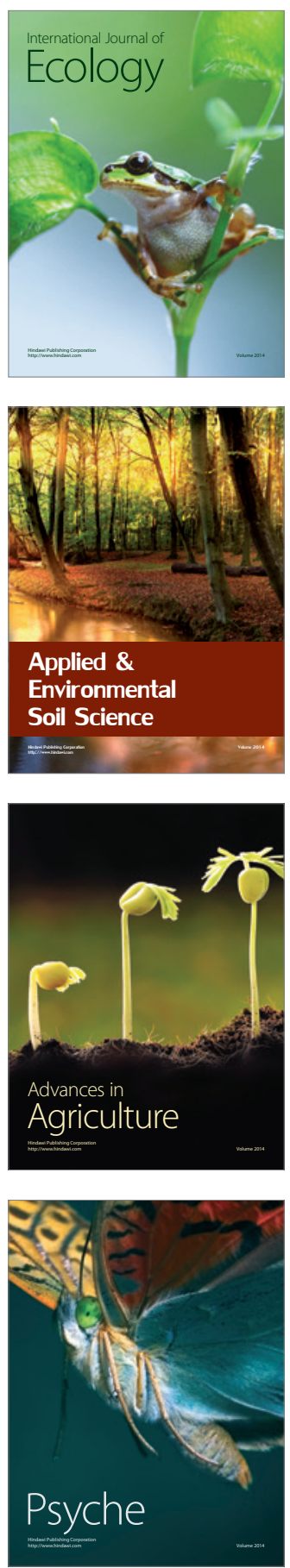